\title{
Effects of online Education by You Tube Channel
}

\author{
Vijay Kumar, J. S. Kalra, Awanish Sharma, Shipra Gupta
}

\begin{abstract}
Today, the way of method of teaching becomes perfectly change for all students. The students do not need to go coaching classes. To understand the real contribution of channel in education, we understand some statistics of an academic channel. In this manuscript a channel is selected for analysis. This study reveals to provide an overall statics of channel, based on age of viewers, mode of traffic sources, name of sharing devices, subscription sources, gender viewers and subscription status over the course of the past 1 year. It is seen that the male viewers of channel are about $74 \%$ and female searched $26 \%$. 92.0\% viewers are learnt by the videos without unsubscribe the channel. It is also observed that the selected channel is seen $82 \%$ by B.Tech students and $16 \%$ by BSc students. $88 \%$ videos are searched by mobile phone device and $10 \%$ students are using computer device. It is concluded in this manuscript that academic videos of you tube channel is playing an important role in study of students.
\end{abstract}

Keywords: You tube channel, online study, students, Traffic Sources, subscription sources.

\section{INTRODUCTION}

In late 2004, 3 PayPal employees - Chad Hurley, Steve Chen, and Jawed Karim - started developing a video dating website. In February 2005 Chad Hurley as CEO registered for trademark, logo and domain for YouTube. It was transformed to video hosting platform in April 2005 on the basis of viewer's feedback. And since then is being used for various types of videos. At present, it is widely used as a platform of learning by the students and faculty members. Before this, no one analyze the importance of these types of videos in education. Any teacher can upload the video on you tube channel and any student can download or watch the video at anytime and anywhere. Every sector is trying to find some or the other way make itself moving in the current situation. Same is with the education sector, teachers are trying their best to reach out to the student in their best way. You tube has been one of the promising platform for the students as well as teachers. As it is free for both the end users, weather the one who uploading the video or the viewer, and the user uploading the video has a bright chance of earning a handsome amount if it is viewed by a good number of users. In this paper we have analyzed our own YouTube channel for various dimensions and tried to figure out some conclusion.

Revised Manuscript Received on August 10, 2019.

Vijay Kumar, Professor, Department of Physics, Graphic Era Hill University, Dehradun, Uttrakhand, India. E-mail: drvijaykumar.geu@gmail.com

J. S. Kalra, A P, Department of Mechanical Engineering, Graphic Era Hill University, Dehradun, Uttrakhand, India. E-mail: jassijaks@ gmail.com Awanish Sharma, Professor, Department of Physics, Graphic Era Deemed to be University, Dehradun, Uttrakhand, India.

Shipra Gupta (Corresponding Author), Associate Professor, Department of Commerce, Graphic Era Hill University, Dehradun, Uttrakhand, India. E-mail:drshipragupta16@gmail.com
Some benefits of videos of YouTube channel are as: The lectures on this platform are always available. Students can attend the lectures at any time anywhere. The access of video lectures may be in mobile phones, computer desktop, laptop, TV, etc.

Students are not required to come college to attend the lectures. Thus classes may be run in this pandemic situation. Students can revise their lecture when he/she wants to do. Lectures may be attended by the students even in night or holidays.

\section{REVIEW OF LITERATURE}

As per Berg, 2016 the publication of Forbes Magazine has published twelve most significant You Tube stars list and estimated about their annual income. In 2017 according to You Tube and Statistics now You Tube has declared their own web page and their earnings are increasing day by day (Borghol 2012, Brodersen A 2012). According to Burgess and Green, 2009 they have explained in their studies that revenue from You Tube videos are increasing about $20 \%$ on average based each year from 2006. So, motivated by earning and other various career options attract to everyone and they want to going with online options (Berg, 2016, Youtube \& Statistics 2017, Youtube \& Developers 2017, Burgess and Green 2009),

Kim 2012, Lobato2016 and Vonderau 2016, state that whenever Google purchased You Tube a number of professional You Tubers' are increasing. As per Kruitbosch and Nack 2008, Welbourne and Grant 2016, Likkanen and Salovaara 2015, and Cunningham et al. 2016, have explained that as per some scholars view it is very difficult to maintain the higher views, comments, voting and content to a larger audience in highly competitive environment (Che X 2015, Welbourne and Grant, 2016, Zhou J 2011).

\section{METHOD}

In this manuscript, we have analyzed a youtube channel which was published in february 2018. Basically the videos uploaded on this channel are for school going as well as university students. The authors prepared the data of watch time hours with respect to viewer gender, subscription status, date of views and devices courses of students. The data also prepared for revenue generation by the sources in you tube channel. The students are studying and completing their course by the use of various online modes. Right now, the maximum suitable and useful mode of studying for the students is you tube channel. 


\section{Effects of online Education by You Tube Channel}

\section{RESULTS AND ANALYSIS}

In this manuscript, the data of different parameters have been given in tables. Observation tables reveals when a student search the topic of his/her subject, he/she can use the various traffic sources. Tables show the watch time of videos, how many times video view, impressions and impression click through rate with respect to the various traffic sources. The traffic sources to search any video by the students may be suggested by you tube search or by other students. Tables also reveals that the video may be searched by the suggestions of other you tube features, by any external agency, by channel pages, browse features etc. As per Sezgintruck M and Sungur S. (2020), no significant differences between gender of students which was done for 222 girls and 239 boys. But table 1 represents that you tube videos are viewed $74 \%$ by male and $26 \%$ by female students. Figure 1 represents the variation in number of views with respect to gender of viewers. Table 2 shows that $92 \%$ students are seeing the videos without subscribed the channel, only $8 \%$ students are viewed the videos after subscription of channel. Watch time and number of views for unsubscribed students are 92 and $91.8 \%$ respectively, while average view duration for unsubscribed and subscribed students are 1:53 and 1:50 respectively. The variation of If students subscribe the channel, then a notification is floated to the student when any new video is uploaded on the channel. Fig 2 shows the variation of Monitoring of watch time (hours), views and average view duration with respect to subscription and unsubscription status. Table 3 shows that it is a property of you tube channel that the lectures can be seen by many devices as mobile phones, computer, tablet, TV and game console etc. This table represents that watch time, views and average view duration for mobile phone device are $88.5 \%, 89.5 \%$ and 1:51 respectively. Similarly for computer $10.1 \%, 9.1 \%$ and 2:06, for tablets $1.0 \%, 1.0 \%$ and $1: 50$, for TV $0.2 \%$, $0.1 \%$ and $2: 09$ and for game console $0.0 \%, 0.0 \%$ and $0: 55$ respectively. The variation of watch times (hours), views and average view duration with respect to various devices is also shown in figure 4.

Table 4 represents that watch time, play list starts, percentage views, average view duration are $81.6 \%, 72.7 \%$, $77.7 \%$ and 1:21 respectively for the students of B.Tech. For BSc students, the given variables will be $16.9 \%, 24.5 \%$, $20.2 \%$ and 1:04 respectively. $1.1 \%, 1.8 \%, 1.4 \%$ and 1:04 are the variables for the students of who are preparing for competitive examinations respectively. For students of class XII, the given variables are $0.0 \%, 0.1 \%, 0.0 \%$ and $0: 57$ respectively. The variation of watch times (hours), playlist starts, views and average view duration with respect to courses of students is also shown in fig. 5 .

Table 5 represents that You tuber can earn money by the advertisements seen on the channel. Figure 6 shows the variation of revenue generation with respect to different sources. It is observed that $64 \%$ revenue can earn by skippable ads, $18 \%$ by bumper ads, $10 \%$ ads by display, and about $7 \%$ ads by non-skippable video ads. As per table 5, by skippable advertisement (auction), Youtube revenue generation is $64.2 \%$ and ad impression is $35.5 \%$ respectively. For bumper ads (auction), Youtube revenue generation is $18.4 \%$ and ad impression is $17.7 \%$ respectively. By Display ads (auction), the above given variables are $10.6 \%$ and $44.2 \%$ respectively, for nonskippable video ads (auction), variables are $6.7 \%$ and $2.5 \%$ respectively.

\section{CONCLUSION}

After studying the analysis of above You Tube channel it has been concluded that there are various traffic sources for watching the videos, but in this channel mostly students searched the topics by the help of key words or titles directly by You Tube and liking videos are mostly shared by whatsApp sharing device. These videos are watched not only in India but also in thirty one other countries also. It is also observed that this channel has watched mostly In India. A You Tuber can get the subscription in many sources, but in this channel the highest subscription source is by You Tube watch page. The videos of this channel have maximum watch time hours and views are lied between 18-24 years aged students. These students are mostly males and mostly videos are watched without subscribed the channel by the use of mobile phone device. These students are mostly Under Graduate and Post Graduate students. Maximum videos are watched by B.Tech students. A You Tuber can get subscription by different advertisement manner. But mostly in this channel You Tuber get the subscription mostly by skippable video Advertisement. In future, the study by you tube channel for students and faculty members become more useful and effective. It may be the revolution in the area of online education.

Table 1: Watch time hours of selected channel with respect to viewer gender

\begin{tabular}{|l|l|l|l|l|l|}
\hline $\begin{array}{l}\text { S. } \\
\text { No. }\end{array}$ & $\begin{array}{l}\text { Viewer } \\
\text { gender }\end{array}$ & $\begin{array}{l}\text { Watch } \\
\text { time } \\
\text { (hours) }\end{array}$ & Views & $\begin{array}{l}\text { Average } \\
\text { view } \\
\text { duration }\end{array}$ & $\begin{array}{l}\text { Average } \\
\text { percentage } \\
\text { viewed }\end{array}$ \\
\hline 1 & Female & $26.0 \%$ & $25.9 \%$ & $1: 53$ & $34.7 \%$ \\
\hline 2 & Male & $74.0 \%$ & $74.1 \%$ & $1: 52$ & $35.1 \%$ \\
\hline
\end{tabular}




\section{watch time}

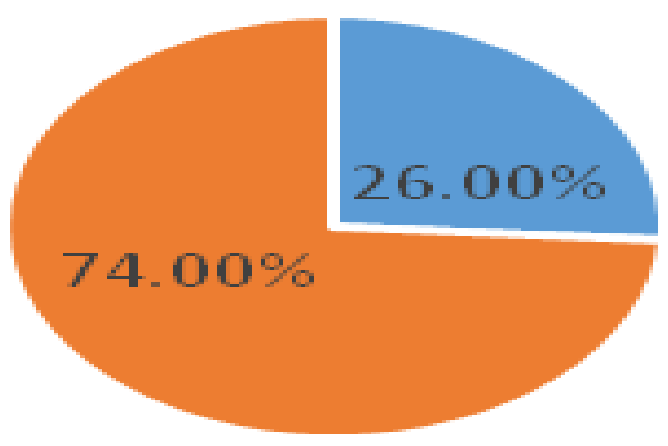

- Female Male

Figure 1: Variation between Watch time with respect to percentage male $\&$ female

Table 2: Monitoring of subscription status of selected

channel

\begin{tabular}{|l|l|l|l|l|l|l|}
\hline $\begin{array}{l}\text { S. } \\
\text { N } \\
\text { o. }\end{array}$ & $\begin{array}{l}\text { Subscripti } \\
\text { on status }\end{array}$ & $\begin{array}{l}\text { Watch time } \\
\text { (hours) }\end{array}$ & \multicolumn{2}{|l|}{$\begin{array}{l}\text { Views } \\
\text { Avera } \\
\text { ge } \\
\text { view } \\
\text { durati } \\
\text { on }\end{array}$} \\
\hline 1 & $\begin{array}{l}\text { Not } \\
\text { subscribe } \\
\text { d }\end{array}$ & $\begin{array}{l}10,444 \\
.4\end{array}$ & $\begin{array}{l}92.0 \\
\%\end{array}$ & $\begin{array}{l}331,2 \\
85\end{array}$ & $\begin{array}{l}91.8 \\
\%\end{array}$ & $1: 53$ \\
\hline 2 & $\begin{array}{l}\text { Subscribe } \\
\text { d }\end{array}$ & 903.0 & $8.0 \%$ & $\begin{array}{l}29,51 \\
0\end{array}$ & $8.2 \%$ & $1: 50$ \\
\hline
\end{tabular}

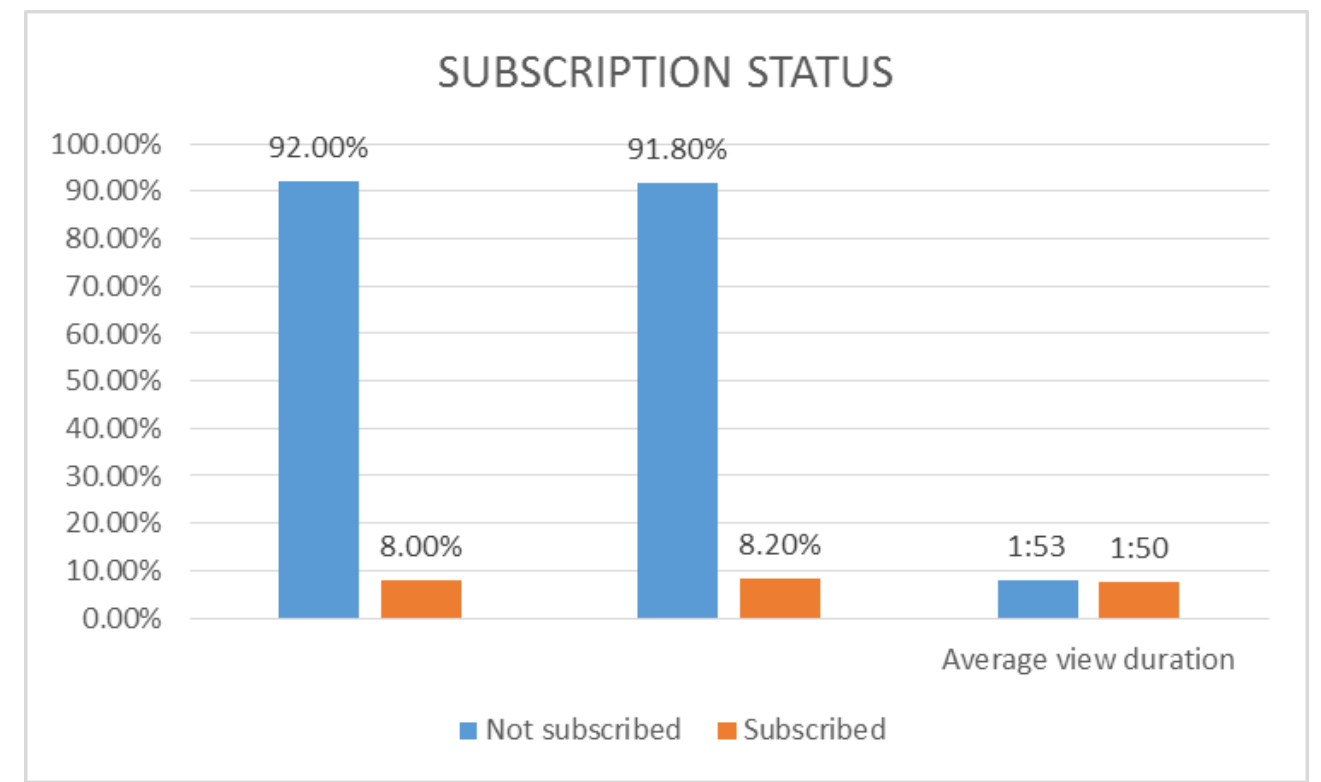

Fig. 2: 


\section{Effects of online Education by You Tube Channel}

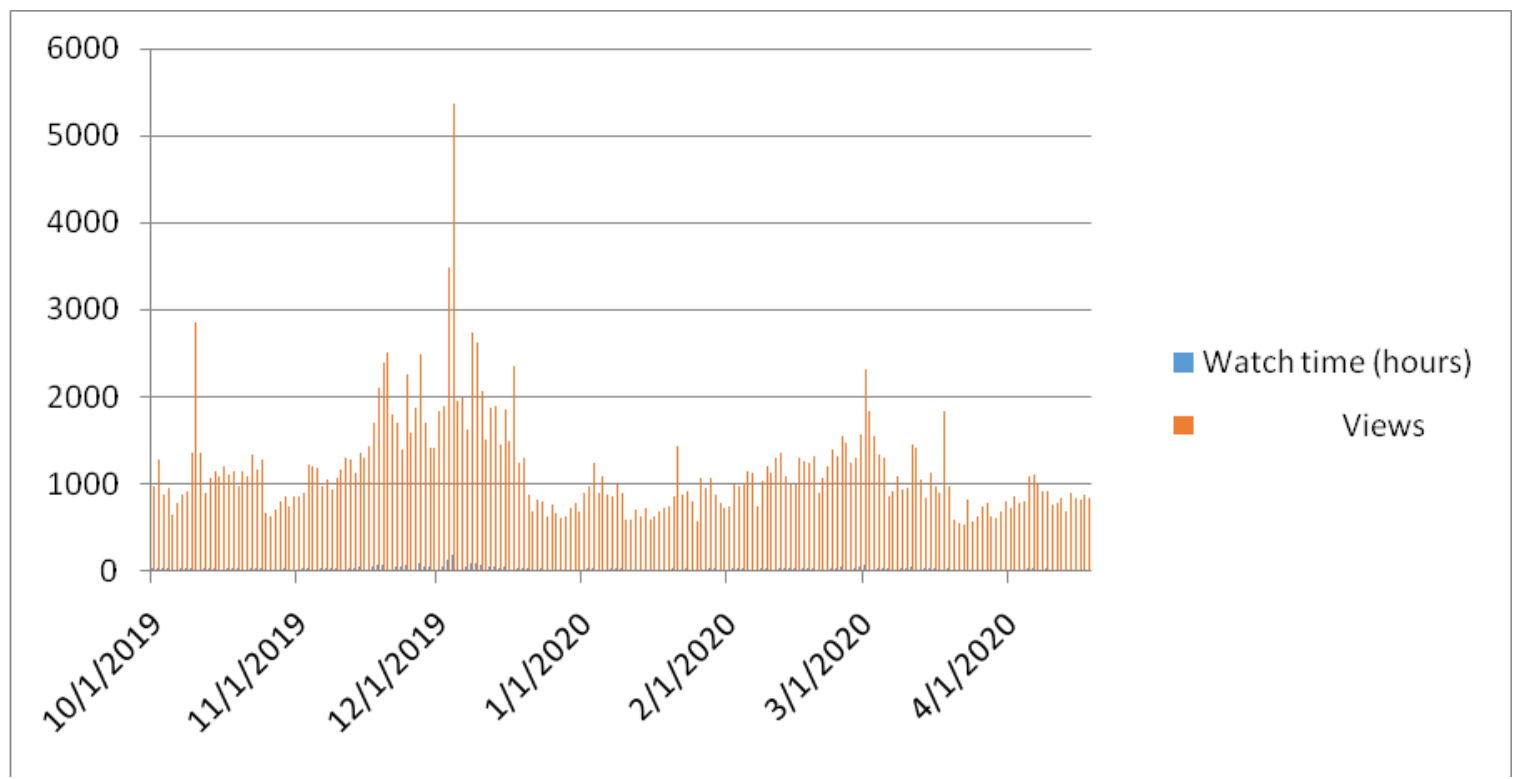

Figure 3: Variation of watch time hours with respect to dates

Table 3: Monitoring of watch times with respect to devices

\begin{tabular}{|c|c|c|c|c|c|c|}
\hline $\begin{array}{c}\text { S. } \\
\text { No. }\end{array}$ & Device type & \multicolumn{2}{|c|}{ Watch time (hours) } & \multicolumn{2}{c|}{ Views } & $\begin{array}{c}\text { Average view } \\
\text { duration }\end{array}$ \\
\hline 1 & Mobile phone & $10,036.80$ & $88.50 \%$ & 322,927 & $89.50 \%$ & $1: 51$ \\
\hline 2 & Computer & $1,151.00$ & $10.10 \%$ & 32,750 & $9.10 \%$ & $2: 06$ \\
\hline 3 & Tablet & 113.9 & $1.00 \%$ & 3,694 & $1.00 \%$ & $1: 50$ \\
\hline 4 & TV & 18.3 & $0.20 \%$ & 507 & $0.10 \%$ & $2: 09$ \\
\hline 5 & Game console & 0.2 & $0.00 \%$ & 10 & $0.00 \%$ & $0: 55$ \\
\hline
\end{tabular}

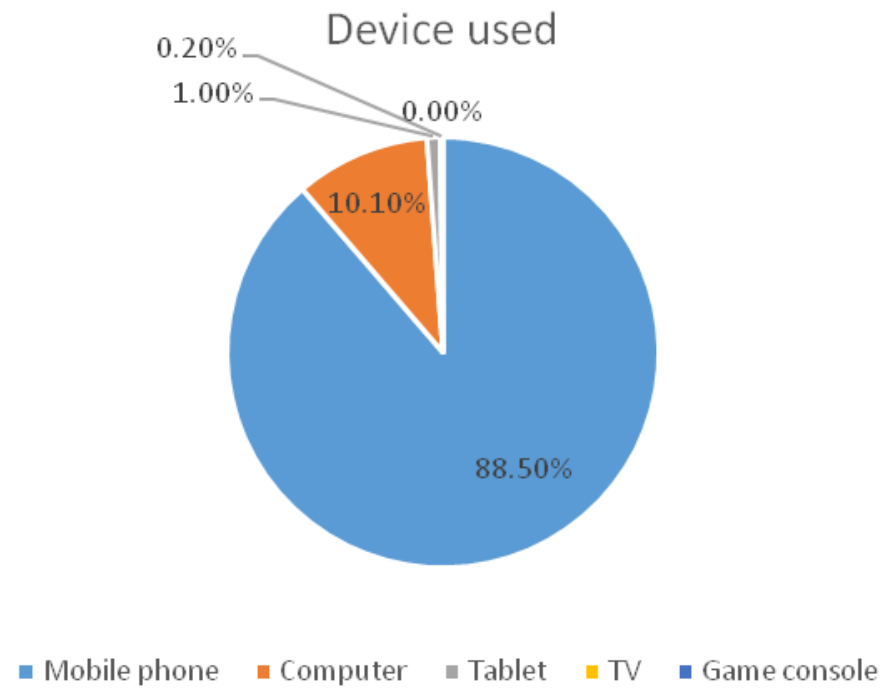

Fig. 3: Variation of watch times with respect to various communication devices

Table 4: Monitoring of watch times with respect to courses of students

\begin{tabular}{|c|c|c|c|c|c|c|c|c|}
\hline S. No. & $\begin{array}{l}\text { Courses } \\
\text { students }\end{array}$ & \multicolumn{2}{|c|}{ Watch time (hours) } & \multicolumn{2}{|c|}{ Playlist starts } & \multicolumn{2}{|c|}{ Views } & $\begin{array}{l}\text { Average } \\
\text { view } \\
\text { duration }\end{array}$ \\
\hline 1 & B.Tech & 59.5 & $81.6 \%$ & 1,031 & $72.7 \%$ & 2,642 & $77.7 \%$ & $1: 21$ \\
\hline 2 & $\mathrm{BSc}$ & 12.3 & $16.9 \%$ & 348 & $24.5 \%$ & 688 & $20.2 \%$ & $1: 04$ \\
\hline 3 & $\begin{array}{ll}\text { Class XI \& } \\
\text { diploma }\end{array}$ & 0.8 & $1.1 \%$ & 25 & $1.8 \%$ & 46 & $1.4 \%$ & 1:04 \\
\hline
\end{tabular}




\begin{tabular}{|l|l|l|l|l|l|l|l|l|}
\hline 4 & $\begin{array}{l}\text { IITJEE \& } \\
\text { NEET } \\
\text { entrance } \\
\text { examinations }\end{array}$ & 0.2 & $0.3 \%$ & 14 & $1.0 \%$ & 23 & $0.7 \%$ & $0: 37$ \\
\hline 5 & Class XII & 0.0 & $0.0 \%$ & 1 & $0.1 \%$ & 1 & $0.0 \%$ & $0: 57$ \\
\hline
\end{tabular}

Table 5: Monitoring of Revenue Generation by Sources

\begin{tabular}{|c|c|c|c|c|c|c|}
\hline $\begin{array}{l}\text { S. } \\
\text { No. }\end{array}$ & Ad type & \multicolumn{2}{|c|}{$\begin{array}{l}\text { YouTube ad revenue } \\
\text { (Indian Rupees) }\end{array}$} & CPM & \multicolumn{2}{|c|}{ Ad impressions } \\
\hline 1 & $\begin{array}{l}\text { Skippable video ads } \\
\text { (Auction) }\end{array}$ & $4,649.88$ & $64.20 \%$ & 149.68 & 31,066 & $35.50 \%$ \\
\hline 2 & Bumper ads (Auction) & $1,332.40$ & $18.40 \%$ & 85.75 & 15,539 & $17.70 \%$ \\
\hline 3 & Display ads (Auction) & 765.42 & $10.60 \%$ & 19.75 & 38,759 & $44.20 \%$ \\
\hline 4 & $\begin{array}{l}\text { Non-skippable video } \\
\text { ads (Auction) }\end{array}$ & 486.9 & $6.70 \%$ & 220.92 & 2,204 & $2.50 \%$ \\
\hline 5 & $\begin{array}{l}\text { Non-skippable video } \\
\text { ads (Reserved) }\end{array}$ & 6.03 & $0.10 \%$ & 194.45 & 31 & $0.00 \%$ \\
\hline 6 & $\begin{array}{l}\text { Skippable video ads } \\
\text { (Reserved) }\end{array}$ & 1.13 & $0.00 \%$ & 24.63 & 46 & $0.10 \%$ \\
\hline 7 & Unknown & 0 & $0.00 \%$ & - & 0 & $0.00 \%$ \\
\hline
\end{tabular}

\section{REFERENCES}

1. Berg, M (2016). The highest-paid YouTube stars 2016: pewdiepie remains no. 1 with $\$ 15$ million. In: Forbes, 5 December 2016. Available

at: http://www.forbes.com/sites/maddieberg/2016/12/05/the-highestpaid-youtube-stars-2016-pewdiepie-remains-no-1-with-15million/\#6b45b38f6b0f (accessed 23 August 2017).

2. Borghol, Y, Ardon, S, Carlsson, N. (2012). The Untold Story of the Clones: Content-Agnostic Factors that Impact Youtube Video Popularity. In: Proceedings of the 18th ACM SIGKDD International Conference on Knowledge Discovery and Data Mining, Beijing, China, 12-16 August 2012, pp 1186-1194. New York: ACM.

3. Brodersen, A, Scellato, S, Wattenhofer, M (2012). YouTube Around the World: Geographic Popularity of Videos. In: Proceedings of the 21st International Conference on World Wide Web, Lyon, France, 16-20 April 2012, pp. 241-250. New York: ACM.

4. Burgess, J, Green, J (2009). The Entrepreneurial Vlogger: Participatory Culture Beyond the Professional-Amateur Divide. In: Snickars, P, Vonderau, P (eds) The YouTube Reader. Stockholm: National Library of Sweden, 89-107.

5. Che, X, Ip, B, Lin, L (2015). A Survey of Current YouTube Video Characteristics. IEEE Multimedia 22(2): 56-63.

6. Cunningham, S, Craig, D, Silver, J (2016). YouTube, multichannel networks and the accelerated evolution of the new screen ecology. Convergence 22(4): 376-391.

7. Kim, J (2012). The institutionalization of YouTube: From usergenerated content to professionally generated content. Media, Culture \& Society 34(1): 53-67.

8. Kruitbosch, G, Nack, F (2008). Broadcast yourself on YouTube: Really? In: Proceedings of the 3 rd ACM International Workshop on Human-Centered Computing, Vancouver, British Columbia, Canada, 31-31 October 2008, pp. 7-10. New York: ACM.

9. Liikkanen, LA, Salovaara, A (2015). Music on YouTube: User engagement with traditional, user-appropriated and derivative videos. Computers in Human Behavior 50: 108-124.

10. Lobato, $\mathrm{R}$ (2016). The cultural logic of digital intermediaries: YouTube multichannel networks. Convergence 22(4): 348-360.

11. Sezgintruck M, Sungur S. (2020), A multidimensional investigation of students science self efficiency: A role og gender, Elementary online education, 19(1), 208-218.
12. Vonderau, P (2016). The video bubble: Multichannel networks and the transformation of YouTube. Convergence 22(4): 361-375.

13. Welbourne, DJ, Grant, WJ (2016). Science communication on YouTube: Factors that affect channel and video popularity. Public Understanding of Science 25(6): 706-718.

14. YouTube \& Statistics. Available at: http://youtube.com/yt/press/statistics.html (accessed 3 September 2017).

15. YouTube \& Developers. Available at: https://developers.google.com/youtube/v3/docs/search/list (accesse d 3 September 2017).

16. Zhou, J, Li, Y, Adhikari, VK. (2011). Counting YouTube Videos via Random Prefix Sampling. In: Proceedings of the 2011 ACM SIGCOMM Conference on Internet Measurement Conference, Berlin, Germany, 2-4 November 2011, 371-380. New York: ACM 